\title{
A Novel Maximum Power Point Tracking Algorithm for Small Wind Power Generator
}

\author{
Yepeng Liu, Weiliang Liu, Yongjie Zhai \\ (North China Electric Power University, Baoding 071003, Hebei Province, China) \\ (1208834919@qq.com,82193745@qq.com,6909249@qq.com)
}

\begin{abstract}
Keywords: small-scale wind power generation, maximum power point tracking (MPPT),variable step hill-climbing method, fuzzy control, Cortex-M4 core
\end{abstract}

\begin{abstract}
This paper introduces the composition of small wind power generation system and the principle of maximum power tracking at first. In order to improve the maximum power point tracking performance of the small-scale permanent magnet synchronous wind power system (WPS), a variable step hill-climbing method suitable for the small-scale WPS based on fuzzy logic control is proposed, which is obviously superior to the traditional fix step hill-climbing. Based on it, the simulation system is built by using Matlab/Simulink. And then the direct-driven WPS experimental platform is constructed with the Cortex - M4 core. Finally, the results of simulation and experiment show that the method can effectively improve the search speed of the system and reduce the system fluctuation.
\end{abstract}

\section{Introduction}

As a stand-alone source for urban area, a small wind turbine generation system is suitable due to the demand of size, noise, and output power. Small wind turbines is an important branch of wind power industry. But the efficiency of small wind generation which is based on existing technical production level is too low owing to the fact that wind has strong randomness and instability. If we can control the system working at the maximum power point, our annual output of wind turbines can be increased by thirty percent, which also helps us to better development of new energy industry.

In order to keep WPS at the maximum point, the method of maximum power point tracking (MPPT) is desirable. The conventional method includes tip speed ratio control, three location power method, power signal feedback control and hill-climbing search. In this paper, MPPT control method using hill-climbing search (HCS) without the anemometer for PMSG small wind turbine generation system has been proposed, which can cause less cost because it requires less sensors.

Fixed step hill-climbing method has a contradiction on search-speed and stability owing to the selection of step disturbance. In this article, we put forward a variable step search method based on the fuzzy logic control, which can solve the problem that disturbance step length is difficult to choose, and it can ameliorate the speediness and stability of the search. To verify the feasibility of the proposed method, the simulation system is built by using Matlab/Simulink. And then the direct-driven WPS experimental platform is constructed with the Cortex - M4 core[1-3].

\section{Mathematical model}

\section{1 wind turbine}

There are two types of wind turbines namely vertical axis and horizontal axis types. Horizontal axis wind turbines usually is used in project due to the advantages of ease in design and lesser cost

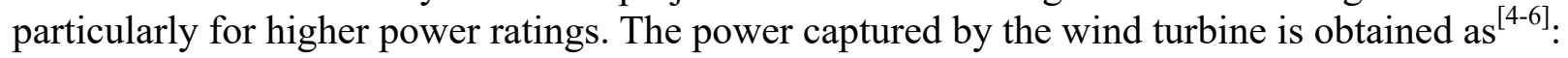

$$
\operatorname{Pm}=\frac{1}{2} \rho \pi r R^{2} C p(\beta, r) V^{3}
$$

The power co-efficient is given by (2): 


$$
\begin{aligned}
& C p(\beta, r)=0.5176\left(\frac{116}{r}-0.4 \beta-5\right) \mathrm{e}^{-\frac{21}{\mathrm{ri}}}+0.068 \\
& \mathrm{r}=\frac{W * R}{V} \\
& \frac{1}{r i}=\frac{1}{r+0.08 \beta}-\frac{0.035}{\beta^{3}+1}
\end{aligned}
$$

In the formulas, $\rho$ is density of the surrounding air, the unit is $\mathrm{kg} / \mathrm{m}^{\wedge} 3$; $\mathrm{V}$ is the natural wind speed, the unit is $\mathrm{m} / \mathrm{s}$; $\mathrm{R}$ is the wind turbine impeller radius, the unit is $\mathrm{m}$; $\mathrm{Pm}$ is wind turbine output mechanical power, unit is $\mathrm{W} ; \beta$ is the blade pitch Angle; $r$ is the tip speed ratio; $w$ is the rotate speed $^{[7]}$.

\subsection{Permanent Magnet Generator}

Permanent Magnet Generator provides an optimal solution for varying-speed wind turbines, of gearless or single-stage gear configuration. Permanent magnet generator under $\mathrm{d}$ - $\mathrm{q}$ rotating coordinate system of ordinary differential equations are as follows:

$$
\begin{aligned}
u_{d} & =R_{s} i_{d}+L_{d} \frac{d i_{d}}{d t}+\frac{d \Psi_{f}}{d t}-w_{e} L_{q} i_{q} \\
u_{q} & =R_{s} i_{q}+L_{q} \frac{d i_{q}}{d t}+w_{e}\left(L_{d} i_{d+\Psi_{f}}\right) \\
T_{e} & =\frac{3}{2} P\left[\Psi_{f} i_{q}+\left(L_{d}-L_{q}\right) i_{q} i_{d}\right]
\end{aligned}
$$

$u_{d} 、 i_{d}, L_{d}$ is voltage, current and inductor in the d axis of rotor respectively; $u_{q} 、 i_{q}, L_{q}$ is voltage, current and inductor in the q axis of rotor respectively; $R_{S}$ is the stator resistance; $w_{e}$ is the rotor angular velocity; $\mathrm{P}$ is the number of polar pairs.

The (6) equation can be simplified as follows due to the fact that permanent magnet motor using surface type permanent magnet.

$L_{d}=L_{q}$

$T_{e}=1.5 P \Psi_{f} i_{q}$

\section{MPPT}

From the working character of wind turbine, it can find that wind turbine has a best work state for variable speed operation, and the maximum power point corresponds to an unique optimal speed. In order to change the speed of the generator, we can disturbance the duty ratio of the BOOST converter from the mathematical model established by the front knowledge. The method of hill-climbing search is applied widely, especially in the photovoltaic industry. It is mainly divided into fixed step length and variable step length. The paper establishes a new variable step search method by using the fuzzy logic control.

\section{1 fix step hill-climbing search}

In conventional fixed step HCS, we exert speed disturbance, then changing the direction of speed disturbance by comparing the measured power signal, which can help us find the maximum power point of wind turbines ${ }^{[8-10]}$. In this way, hill-climbing search is to reach the top like to climb mountain. It is mainly divided into four different situations:

(1) $\mathrm{P}(\mathrm{K})>\mathrm{P}(\mathrm{K}-1), \mathrm{V}(\mathrm{K})>\mathrm{V}(\mathrm{K}-1)$. This suggests that the wind turbine is still working on the left side of the maximum power point, and the disturbance direction should be the same.

(2) $\mathrm{P}(\mathrm{K})>\mathrm{P}(\mathrm{K}-1), \mathrm{V}(\mathrm{K})<\mathrm{V}(\mathrm{K}-1)$. This suggests that the wind turbine is still working on the right side of the maximum power point, and the disturbance direction should be the same.

(3) $\mathrm{P}(\mathrm{K})<\mathrm{P}(\mathrm{K}-1), \mathrm{V}(\mathrm{K})>\mathrm{V}(\mathrm{K}-1)$. The disturbance direction should be the opposite.

(4) $\mathrm{P}(\mathrm{K})<\mathrm{P}(\mathrm{K}-1), \mathrm{V}(\mathrm{K})<\mathrm{V}(\mathrm{K}-1)$, The disturbance direction should be the opposite.

This method includes two mainly problems: firstly, large fixed step length can shorten search time, but the stability will be caused bad influence. Secondly, if shorten the step length, it is not suitable for big inertia system. 


\subsection{MPPT based on fuzzy logic control}

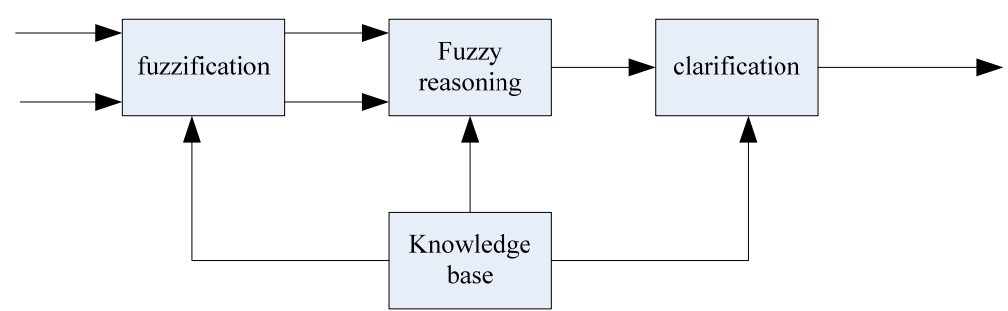

Fig2. Fuzzy control block diagram

Fuzzy processing, fuzzy reasoning and defuzzification compose a fuzzy logic control system. For most of the complex controlled object, the traditional control method is often difficult to get satisfactory control result. Fuzzy control technology has the ability to deal with uncertainty and fuzzy information words, which has been proved to be an effective method that solve many complex modeling and control problem.

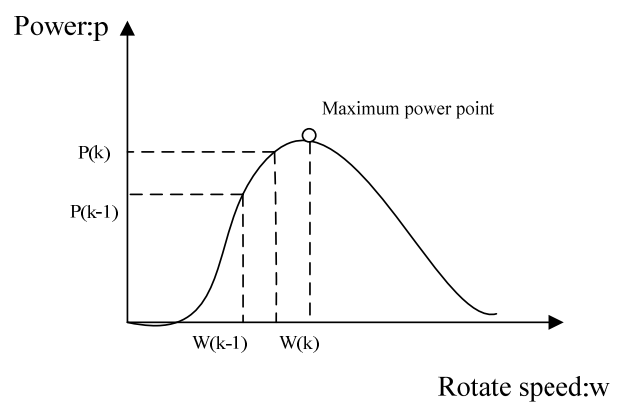

Fig3. Performance curve of wind turbine

According to the figure 3 , the conclusions are as summarized as follows: duty ratio $\Delta \mathrm{W}$ has bigger influence on the output power of the wind turbine as the work point is far away from the optimal location. The slope of each point varies according to the distance from the maximum power point .The paper chooses power variation $E$ (n) for the input of fuzzy controller.

\section{3 fuzzy controller}

\section{(1) Fuzzification}

Power variation $(\Delta \mathrm{P})$ and last time's duty variation $\Delta \mathrm{D}(\mathrm{K}-1)$ are used as the inputs of the proposed FLC-based MPPT controller. $\triangle \mathrm{D}(\mathrm{K})$ is used as the output of FLC. K is the quantification factor of inputs and output. Their fuzzy subset are as follows:

$$
\begin{gathered}
E_{P}=\{N B, N M, N S, N O, P O, P S, P M, P B\} \\
E_{D(K-1)}=\{N B, N M, N S, Z O, P S, P M, P B\} \\
E_{D(K)}=\{N B, N M, N S, Z O, P S, P M, P B\}
\end{gathered}
$$

For linguistic variables, $\mathrm{P}$ represents positive, $\mathrm{N}$ represents negative, $\mathrm{B}, \mathrm{S}$, and $\mathrm{ZE}$ are defined as big, small and zero, respectively. The Membership functions of the utilized input and output variables for the proposed controller are illustrated in Figure 6.Both the inputs and output are in triangular form. From Figure 6, each of the power variables is mapped into eight different linguistic values, and the duty variable is mapped into seven linguistic values. Therefore, the proposed FLC will contain 56 different rules. 


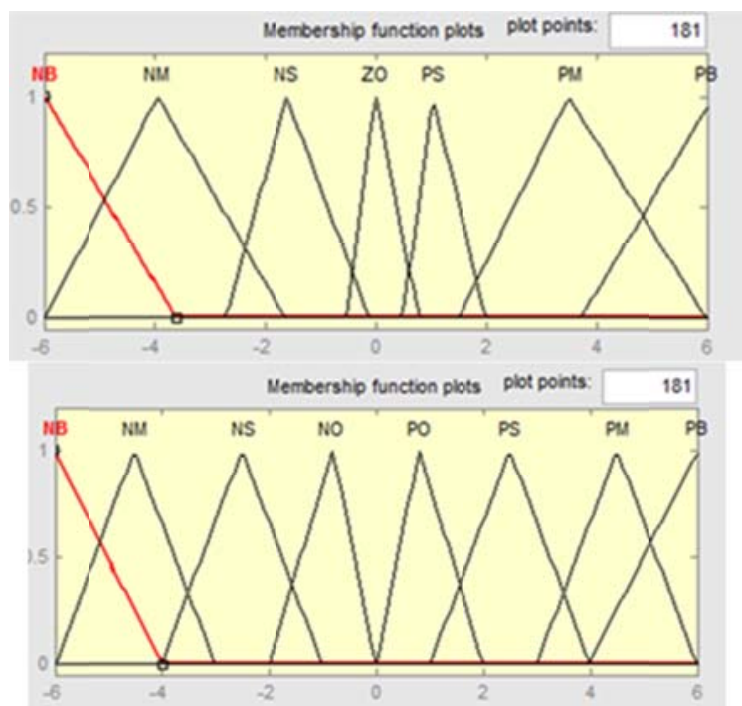

(2) Fuzzy rules

Fig4. Member function of the power variation and duty variation

For control rule design, since $\Delta \mathrm{P}$ and $\Delta \mathrm{D}(\mathrm{K}-1)$ are taken as the inputs and $\Delta \mathrm{D}(\mathrm{K})$ is chosen as the output in this paper. According to the actual characteristics of small wind turbine system, the basic principle of designing the rules is explained as follows:

1) If $\Delta \mathrm{P}$ is positive, it indicates that the operating point goes toward the maximum power point (MPP). Keep sign of the output variable $\Delta \mathrm{D}$. On the other hand, change sign of the output.

2) If the operating point is far away from the MPP, increase the output variable $\Delta \mathrm{D}$. A larger $\Delta \mathrm{D}$ is required to rapidly reach the MPP. On the contrary, when the operating point is close to the MPP, a smaller $\Delta \mathrm{D}$ can be used to reduce the fluctuation on steady state.

Table 1. Complete rule base

\begin{tabular}{|c|c|c|c|c|c|c|c|c|c|}
\hline \multirow[b]{2}{*}{$\mathrm{D}(\mathrm{n})$} & & \multicolumn{8}{|c|}{$E(n)$} \\
\hline & & NB & NM & NS & $\mathrm{NO}$ & $\mathrm{PO}$ & PS & PM & PB \\
\hline \multirow{7}{*}{$\begin{array}{l}D(n-1 \\
)\end{array}$} & NB & PB & PM & PS & PS & NS & NS & NS & NS \\
\hline & NM & $\mathrm{PB}$ & PM & PM & PS & NS & NS & NS & NS \\
\hline & NS & PB & PB & PM & PS & NS & NS & NS & NS \\
\hline & $\mathrm{ZO}$ & NS & $\mathrm{PB}$ & $\mathrm{PO}$ & NS & PS & NS & NS & NS \\
\hline & PS & NS & NS & NS & NS & PS & PM & PM & PB \\
\hline & PM & NS & NS & NS & NS & PS & PM & PM & PB \\
\hline & PB & NS & NS & NS & NS & PS & PS & PB & PB \\
\hline
\end{tabular}

(3) Defuzzification

The defuzzification method used in this paper is the commonly used center of gravity method as shown in equation :

Yo $=\frac{\sum_{1}^{n} Y i(X i) X i}{\sum_{1}^{n} Y i(X i)}$

where $\mathrm{Yi}$ is the inference result of rule $\mathrm{i}$; $\mathrm{Xi}$ is the corresponding output of rule $\mathrm{i}$; and Yo is the output.

\section{Experimental Results}

\subsection{The simulation parameter Settings}

To verify the feasibility of the proposed method, the simulation system is built by using Matlab/Simulink. The whole simulation model includes wind turbine, PMSG, the rectifier the BOOST chopper. The rotor radius $\mathrm{R}$ is $0.65 \mathrm{~m}$; Air density is $1.225 \mathrm{~kg} / \mathrm{m}^{\wedge} 3$; Wind speed is $4-10 \mathrm{~m} / \mathrm{s}$; wind turbine pitch Angle $\boldsymbol{\beta}$ is 0 .

The part of the logic control is built by using the MATLAB fuzzy control toolbox. The 
quantitative factors of input selection is 1.5, and the output of quantitative factor selection is 0.01. Sampling time is set to $\mathrm{T}=0.005 \mathrm{~S}$, MPPT module calculates one time in $5 \mathrm{~T}$.

\subsection{The results of simulation}

(1) When wind speed is $10 \mathrm{~m} / \mathrm{S}$, the performance curve of fix-step MPPT and MPPT based on FLC

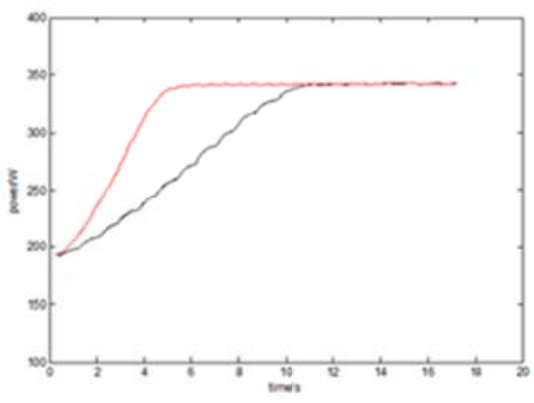

Fig5.The power curve based on FLC and fix step HCS

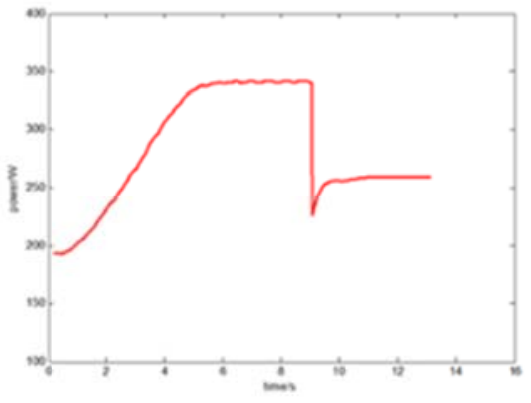

Fig6. The power curve of FLC

(2) Wind speed decreases from $10 \mathrm{~m} / \mathrm{S}$ to $9 \mathrm{~m} / \mathrm{S}$

We can see from the Fig5 and Fig6, the method Based on the FLC has faster response speed than the fixed step, and the oscillation near the maximum power point is smaller.

\subsection{Experimental platform}

In order to verify the correctness of this method, we built a small permanent magnet wind power generation system. The system includes permanent magnet wind power generator, three-phase uncontrolled diode rectifier circuit, Boost booster circuit, and the experimental load.

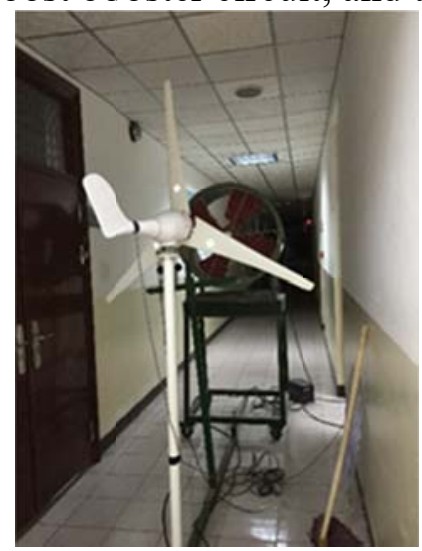

Fig7. The experiment platform facilities

The microcontroller is Freescale LQ_K60P144 - SYSVG, and the core is Cortex - M4. It is worth mentioning that we fix a photoelectric rotary encoder in the permanent magnet wind turbine, and the rotor speed can be measured very sensitive. The natural wind is simulated by the blower. The curve that we have received is not so smooth because the sensor acquire instable signal. But from the trend of the curve, this method can still achieve maximum power tracking very well.

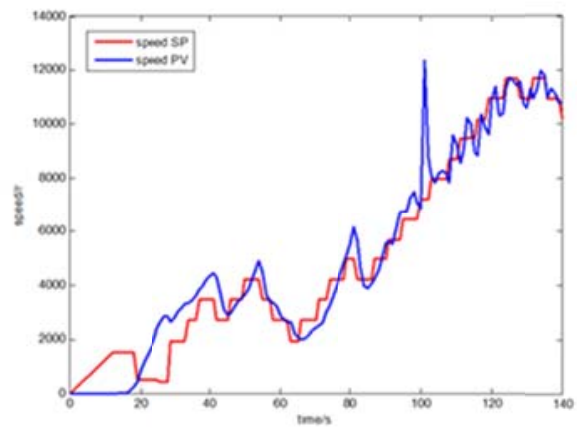

Fig8. The speed curve of wind turbine

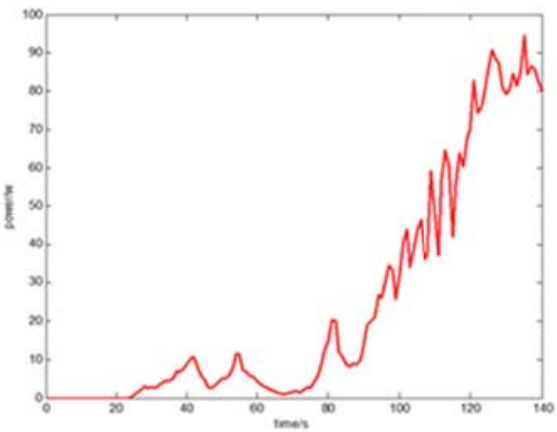

Figure9. The power curve of wind turbine

According to the experimental result, when rotor speed reaches $11 \mathrm{r} / \mathrm{s}$, power achieve maximum $85 \mathrm{~W}$. 


\section{Conclusion}

The paper analyzes the working characteristics of wind turbine and proposes a new method of variable step's MPPT based on FLC. Simulation and experimental results show that the wind turbine can quickly reach maximum power point and increase the stability by using the new method. When wind speed changes, it still has a strong adaptability. The real experiment platform also verify the effectiveness of this method.

\section{References}

[1]Song M X. Simulation and Hardware Implementation of Incremental Conductance MPPT With Direct Control Method Using Cuk Converter[J]. IEEE Transactions on Industrial Electronics, 2010, 58(4):1154-1161.

[2]Jones A D, Underwood C. A Thermal model for photovoltaic systems[J]. Solar Energy, 2001, 70(4):349-359.

[3]Koizumi H, Mizuno T, Kaito T, et al. A Novel Microcontroller for Grid-Connected Photovoltaic Systems[J]. IEEE Transactions on Industrial Electronics, 2006, 53(6):1889-1897.

[4]Xia Y, Ahmed K H, Williams B W. A New Maximum Power Point Tracking Technique for Permanent Magnet Synchronous Generator Based Wind Energy Conversion System[J]. IEEE Transactions on Power Electronics, 2011, 26(12):3609-3620.

[5]Abo-Khalil A G, Lee D C. MPPT Control of Wind Generation Systems Based on Estimated Wind Speed Using SVR[J]. Industrial Electronics IEEE Transactions on, 2008, 55(3):1489-1490.

[6]Zadeh L A. Fuzzy Logic = Computing with Words[J]. IEEE Transactions on Fuzzy Systems, 1999, 4(2):3-23.

[7]Akiyama Y, Higuchi K. Fuzzy objects-another way of understanding fuzzy logic by computing with words[C]// IEEE International Conference on Systems, Man, and Cybernetics. IEEE, 1997:2945-2950 vol.3.

[8]Kim J S, Sul S K. New approach for high performance PMSM drives without rotational position sensors[J]. IEEE Transactions on Power Electronics, 1995, 12(5):381 - 386. 